\title{
Brain white matter lesions in HAM/TSP: do they have any special meaning?
}

Lesões cerebrais na HAM/TSP: qual o seu significado?

Otávio Augusto Moreno-Carvalho

MD, Infectologist, Neurologist and CSF Specialist, Fundação José Silveira, Salvador BA, Brazil.

Correspondence:

Otávio Augusto Moreno-Carvalho Rua Professor Aristides Novis, 105 /1201B

40210-630 Salvador BA - Brasil E-mail: nascimentocarvalho@ hotmail.com

Conflict of interest:

There is no conflict of interest to declare.

Received 29 February 2012 Received in final form 02 March 2012 Accepted 09 March 2012
$\mathrm{H}$ uman T-cell lymphotropic virus type I (HTLV-I)-associated myelopathy/tropical spastic paraparesis (HAM/TSP) is a disease that is clinically characterized by unremitting myelopathic symptoms, such as spastic paraparesis, lower back pain, bladder dysfunction, and mild sensory disorders of the limbs, which are symmetrical in most patients ${ }^{1}$.

HTLV-I infection is a necessary condition for the development of HAM/TSP, but is insufficient on its own for this to occur. Risk factors play a pivotal role as disease "determinants". High proviral load (PVL)>1\% peripheral blood mononuclear cells, PBMCs) ${ }^{2,3}$, age, HTLV-I subtypes, and gender have been recognized as important risk factors. Interestingly, not only some host genetic factors have been identified as noteworthy risk factors, but also other factors have been identified as highly protective ones against the development of the disease ${ }^{4-6}$.

Even though the pathological mechanisms for HAM/TSP so far remain incompletely understood, a great deal of knowledge has been gained in this regard. The majority (around 95\%) of HTLV-I-infected individuals develop a strong, efficient, and protective CD8+ cytotoxic T-lymphocyte (CTL) response against the virus. It prevents an expansion of the infected target cells (CD4+ T cells), reduces the proviral load and keeps it under control, and therefore the disease does not develop (phase 0 of infection*). Nevertheless, when HTLV-I infection is combined with pivotal risk factors, the CTL protective response against HTLV-I will, at some point in time, gradually turn into a deregulated strong response to HTLV-I infected target cells. Consequently, an inflammatory reaction occurs, characteristically involving the watershed zones of the spinal cord and also, to a lesser extent, involving the brain ${ }^{7,8}$. In these regions, the vascular architecture leads to a slowing of the blood flow. The disease then starts and progresses over a period of years (phase 1 of infection*). After that, the patients enter into a stage characterized by spinal cord scarring and sequelae (phase 2 of infection*).

Phase 1 starts when the target cells influenced by the HTLV-I tax protein promote expression of the ligands on their surface, which starts production of pro-inflammatory cytokines such as IFN-gamma, TNF-alpha and IL-2, and also of the chemoattractant factor MCP-1. On the other hand, IFN-gamma induces expression of adhesion molecules in the endothelial cells of the microvessels of the watershed zones. Therefore, this combined activity leads to chemotaxis, adhesion and migration, not only of the infected target cells, but also of the CTLs from the vascular compartment into the CNS tissue itself. As a consequence of IL-2 stimulus, CTLs proliferate and this leads to target cell apoptosis. Macrophages phagocytize apoptotic target cells, become infected and, under the influence of the HTLV-I Tax protein, produce MIP and other chemokines. This increases CTL degranulation and leads to greater apoptosis of the HTLV-I-infected target cells. Moreover, many other cytokines, chemoattractants and immunological molecules also play an important role in the HAM/TSP pathogenesis.

Histopathologically, the disease affects the spinal cord, and mainly at the thoracic level, where the damage is most severe in the middle to lower regions. Degeneration is seen in the lateral corticospinal tract as well as in the spinocerebellar or spinothalamic tract of the lateral column 7 . Perivascular and parenchymal lymphocytic infiltration, along with foamy macrophages, astrocyte proliferation and fibrillary gliosis, is seen in such lesions ${ }^{9}$. The widespread loss of myelin and axons are noteworthy, particularly in the corticospinal tracts of the spinal 
cord. These data explain neurological symptoms, such as paraparesis, spasticity, hyperreflexia and Babinski's sign, which are characteristics of the disease ${ }^{9}$.

Osame has proposed an interesting hypothesis to explain the neurological damage that occurs in HAM/TSP cases. According to this hypothesis, the presence of inflammatory cells and molecules such as TNF-alpha and IFNgamma, among others, would damage "bystander" neural tissue ${ }^{10}$.

This issue of Arquivos de Neuro-Psiquiatria presents a very interesting, prospective and descriptive, study by Marzia Puccioni-Sohler et al. ${ }^{11}$, in which they searched for answers by analyzing associations between clinical characteristics, findings of inflammatory CSF, and white matter lesions of the brain and cervical spinal cord observed on the magnetic resonance imaging (MRI), among 28 Brazilian HAM/TSP patients seen at the Neuroinfection Outpatient Clinic of the Federal University of Rio de Janeiro, from 2006 and 2011. Their main goal was to clarify the origin and significance of white matter lesions in the brains of HAM/TSP patients. They came to the conclusion that such lesions were nonspecific and unrelated to the clinical characteristics of HAM/TSP. They also made the interesting suggestion that the proximity of some cervical lesions to the CSF compartment can be correlated with the intensity of CSF alterations.

In summary, the cardinal neurological symptoms of HAM/TSP are due to the loss of myelin and axons in the spinal cord, mainly at the thoracic level and very likely as a consequence of the inflammatory reaction.

*Author's classification.

\section{References}

1. Matsura E, Yamano Y, Jacogson S. Neuroimmunity of HTLV-I infection.J Neuroimmune Pharmacol 2010;5:310-325.

2. Nagai M, Usuku K, Matsumoto W, et al. Analysis of HTLV-I proviral load in 202 HAM/TSP patients and 243 asymptomatic HTLV-I carriers: high proviral load strongly predisposes to HAM/TSP. J Neurovirol 1998;4:586-593.

3. Taylor GP, Tosswill JH, Matutes E, et al. Prospective study of HTLV-I infection in an initially asymptomatic cohort. J Acquir Immune Defic Syndr 1999;22:92-100.

4. Jeffery KJ, Usuku K, Hall SE, et al. HLA alleles determine human T-lymphotropic virus-I (HTLV-I) proviral load and the risk of HTLV-I-associated myelopathy. Proc Natl Acad Sci USA 1999;96: 3848-3853.

5. Jeffery KJ, Siddiqui AA, Bunce M, et al. The influence of HLA class I alleles and heterozygosity on the outcome of human T cell lymphotropic virus type I infection. J Immunol 2000;165:7278-7284.

6. Vine AM, Witkover AD, Lloyd AL, et al. Polygenic control of human T lymphotropic virus type I (HTLV-I) provirus load and the risk of HTLV-
I-associated meolapathy/tropical spastic paraparesis. J Infect Dis 2002;186:932-939.

7. Izumo S, Ijichi T, Higuchi I, Tashiro A, Takahashi K, Osame M. Neuropathology of HTLV-I-associated myelopathy - a report of two autopsy cases. Acta Paediatr Jpn 1992;34:358-364.

8. Moe Moe Aye, Matsuoka E, Moritoyo Umehara F, et al. Histopathological analysis of four autopsy cases of HTLV-I-associated myelopathy/tropical spastic paraparesis: Inflammatory changes occur simultaneously in the entire central nervous system. Acta Neuropathol 2000;100:245-252.

9. Umehara F, Izumo S, Nakagawa M, et al. Immunocytochemical analysis of the cellular infiltrate in the spinal cord lesions in HTLV-I-associated myelopathy. J Neuropathol Exp Neurol 1993;52:424-430.

10. Osame M. Pathological mechanisms of human T-cell lymphotropic virus type I-associated myelopathy (HAM/TSP). J Neurovirol 2002;8:359-364.

11. Puccioni-Sohler M, Gasparetto E, Cabral-Castro MJ, et al. HAM/TSP: association between white matter lesions on magnetic resonance imaging, clinical and cerebrospinal fluid findings. Arq Neuropsiquiatr 2012;70:246-252 